\title{
Interação entre Crianças com Necessidades Especiais em Contexto Lúdico: Possibilidades de Desenvolvimento
}

\author{
Interaction among Children with Special Needs in Free-Play Situations: \\ Possibilities of Development
}

\author{
Carolina Molina Lucenti de Souza* \& Cecilia Guarnieri Batista \\ Universidade Estadual de Campinas, Campinas, Brasil
}

\begin{abstract}
Resumo
O trabalho discute o papel dos parceiros, em contexto lúdico, no processo de desenvolvimento da criança com necessidades especiais. Foram observadas, em situação de brincadeira, as interações entre crianças de 4-12 anos, com diagnóstico de deficiência visual (baixa visão ou cegueira), muitas com problemas orgânicos adicionais e dificuldades de aprendizagem. Foram selecionados episódios representativos das capacidades dessas crianças, e estes permitiram a identificação de dois grupos de categorias: (a) modos de brincar (individual ou em grupo); (b) modos de se relacionar (amistoso ou agonístico) das crianças. A análise dos dados indicou a importância da interação entre pares no processo de desenvolvimento das crianças com necessidades especiais e revelou a situação de brincadeira como espaço favorável para a construção dessas interações.

Palavras-chaves: Deficiência visual e múltipla; brincadeira faz-de-conta; interação entre crianças; educação especial.
\end{abstract}

\begin{abstract}
The present study discussed the role of peer interaction, in a free-play situation, to the development of children with special needs. The interactions between visually impaired children (low vision or blindness), most of them with additional organic problems and/or learning difficulties, were observed in a free-play situation. The investigation of episodes which were representative of different abilities of the children lead to the identification of two categories: (a) ways of playing (individually or in group), and (b) kinds of relationships between peers (friendly or agonistic). The analysis pointed to peer interaction as an important contributing factor to the development of children with special needs and suggested that free-play situations can constitute favorable settings for the construction of those interactions.

Keywords: Visual and multiple impairments; make-believe play; peer interaction; special education.
\end{abstract}

Os estudos voltados para as relações entre pares têm destacado o papel da criança na interação social como um elemento importante a ser considerado no processo de construção, desenvolvimento e transformação do indivíduo, da cultura e da sociedade. Esses trabalhos apontam para a criança como um ser humano complexo, capaz de despertar em seus parceiros habilidades e capacidades (Carvalho \& Beraldo, 1989; Carvalho \& Pedrosa 2002; Góes, 1995; Pedrosa \& Carvalho, 1995).

Quando se trata de crianças com necessidades especiais, as questões relacionadas à interação social se tornam ainda mais importantes, já que, por possuírem algumas limitações, por exemplo, quanto às possibilidades de locomoção e exploração de objetos, são freqüentemente consideradas incapazes de participar e contribuir nas atividades em grupo. Deste modo, as crianças com necessidades especiais são, muitas vezes, isoladas do contato com

\footnotetext{
*Endereço para correspondência: Universidade Estadual de Campinas, Cepre - Faculdade de Ciências Médicas, Rua Tessália Vieira de Camargo, 126, Bairro Barão Geraldo, Campinas, SP, 13089-971. Caixa Postal 6111. E-mails: carolmls@uol.com.br e cecigb@fcm.unicamp.br
}

parceiros e têm suas interações restritas à relação com o adulto. Esse isolamento pode ocorrer nas relações com parentes e vizinhos, na escola, e nas relações de caráter terapêutico.

Guralnick $(1997,2002)$ vem desenvolvendo trabalhos relacionados ao desenvolvimento infantil e a processos de intervenção no caso de crianças com deficiências. Alguns desses trabalhos se interessam pelas relações em grupo e estabelecimento de amizades entre crianças de idade préescolar com atraso moderado de desenvolvimento. De acordo com Guralnick (1997), a interação entre pares em casa, na vizinhança, na comunidade e na escola constitui um importante elemento da vida social da criança, pois promove um contexto propício ao desenvolvimento de suas competências sociais. Entretanto, referindo-se a alguns de seus estudos anteriores, Guralnick (2002) menciona que crianças com deficiência intelectual moderada correm o risco de serem socialmente isoladas da interação com pares. Por meio de comparações com crianças de mesma faixa etária que apresentam desenvolvimento típico o autor relata: um número restrito de amizades formadas por crianças com deficiência intelectual; dificuldades de esta- 
belecer um bom desenvolvimento nas atividades em grupo e menor freqüência de participação dos pares; menor aceitação dos grupos e menor integração social em programas de pré-escola inclusiva. $\mathrm{O}$ autor observa também que o envolvimento da criança no grupo pode variar individualmente por características específicas de cada uma e possivelmente pelo empenho dos pais em propiciar relações dos filhos com parceiros. Guralnick (1997) verifica ainda que, apesar das crianças com deficiência intelectual serem mais dependentes dos pais no envolvimento em grupos de brincadeira do que aquelas com desenvolvimento típico, seus pais tendem a organizar grupos de brincadeiras entre pares com menos freqüência que os pais de crianças sem alterações.

$\mathrm{O}$ autor salienta que embora haja um rápido aumento no conhecimento sobre os processos de interação de crianças com desenvolvimento típico, são limitadas as informações disponíveis quanto às crianças com atraso geral de desenvolvimento. Guralnick (1997) ressalta a seriedade do problema, já que dificuldades relatadas na pré-escola relativas à competência social entre pares dessas crianças podem contribuir para seu isolamento social.

Focando o desenvolvimento de crianças cegas, Preisler (1997) relata um estudo longitudinal qualitativo com oito crianças com cegueira congênita desde o nascimento até os seis anos, com um follow up aos 10 anos. Essas crianças apresentaram aquisições nos aspectos cognitivos e motores de acordo com as solicitações do currículo da escola regular. Por outro lado, as dificuldades observadas estavam centradas nos aspectos sócio-afetivos. Ao longo de todo o período pré-escolar, as crianças do estudo de Preisler (1997) encontraram dificuldades de se envolverem em atividades de brincadeira livre com crianças videntes e se limitaram a interagir com o adulto ou a brincarem sozinhas. Segundo a autora, isso se deu principalmente devido à pouca disponibilidade de brinquedos interessantes para as crianças cegas, já que na maioria deles predominavam atrativos visuais, e ao fato de que, na brincadeira livre, as crianças videntes interagiam predominantemente por meios não verbais, como expressões faciais e movimentos corporais, que dificultavam a participação da criança cega. A autora conclui apontando para a necessidade de maior atenção para o estudo do desenvolvimento social das crianças cegas.

Nota-se uma tendência de atribuir as dificuldades enfrentadas no desenvolvimento das crianças com deficiência a seus problemas orgânicos, reduzindo ou anulando as influências das condições ambientais nas quais estão inseridas. No entanto, é possível verificar que a limitação orgânica pode não ser a única condição responsável pelas dificuldades cognitivas dessas crianças. Como discutido por Vygotsky (1974/1997), as dificuldades reais das crianças com necessidades especiais não estão diretamente relacionadas a seus problemas orgânicos, mas se devem aos modos de interpretação social desses problemas. Deve-se, então, considerar as oportunidades reduzidas de contato com objetos da sua cultura e de estabelecimento de relações sociais com parceiros como fatores que podem difi- cultar o desenvolvimento dessas crianças. Nesse sentido, o favorecimento da interação entre parceiros pode contribuir para os processos de construção e transformação de significados, no desenvolvimento da criança com necessidades especiais.

Surge, então, a pergunta sobre as condições que poderiam propiciar a relação entre pares. Dentre estas, a situação de brincadeira se destaca, por ser uma atividade naturalmente buscada pelas crianças, e por ser descrita como de fundamental importância para o desenvolvimento infantil. Huizinga (1971) trata o jogo como um fenômeno cultural, salientando que este é carregado de significado e dotado de um elemento que transpõe o material e que torna insuficientes as explicações que buscam lhe dar uma finalidade biológica. O autor relaciona o brincar com características como a liberdade, a espontaneidade e o prazer. Suas reflexões ressaltam a motivação própria do jogo (centrada no processo e não no produto) e revelam importantes características relativas ao predomínio do caráter cultural dessa atividade e à sua importância para o desenvolvimento do ser humano.

Vygotsky (1978/1991) dá ênfase à constituição social do brincar como parte do desenvolvimento cultural da criança, e destaca sua contribuição para o desenvolvimento global do pré-escolar. Vê o brinquedo como o instrumento que preenche as necessidades que não podem ser satisfeitas na situação "real", como o meio pelo qual a criança se apropria do mundo.

O brinquedo fornece ampla estrutura básica para mudanças das necessidades e da consciência. A ação na esfera imaginativa, numa situação imaginária, a criação das intenções voluntárias e a formação dos planos da vida real e motivações volitivas - tudo aparece no brinquedo, que se constitui, assim, no mais alto nível de desenvolvimento pré-escolar. A criança desenvolvese essencialmente, através da atividade de brinquedo. (Vygotsky, 1978/1991, p. 117).

Também com um referencial histórico-cultural, uma contribuição recente é apresentada por Sinha (2005). O autor avalia o jogo simbólico como um exemplo de:

cognição virtual, no qual o imaginário e o real se fundem ou combinam na arena das experiências em que o 'mental' e o 'físico' são dissociados de suas correlações costumeiras, convencionais ou canônicas, e re-arranjados em um espaço novo, combinado. (p. 1547).

$\mathrm{O}$ autor sugere que o conhecimento dos jogadores sobre o jogo dirige suas ações e supera as affordances ${ }^{1}$ imediatas e convencionais do ambiente físico. Sinha (2005) considera "o jogo simbólico como importante passo para a atualização do poder simbólico da linguagem como veículo para a construção de espaços mentais imaginários" (p. 1547). Ressalta, entretanto, que esse "passo significativo não se dá pela 'retirada' ou 'substituição' do mundo material real presente no setting. Ao invés disso, o setting real fica como

${ }^{1}$ Termo para indicar as manipulações permitidas pelas características físicas do objeto. 
Souza, C. M. L. \& Batista, C. G. (2008). Interação entre Crianças com Necessidades Especiais em Contexto Lúdico: Possibilidades de Desenvolvimento.

pano de fundo, e é então reincorporado ao espaço do jogo simbólico" (p. 1547-1548). Para ele, os processos envolvidos no jogo freqüentemente envolvem a negociação social de valores simbólicos a serem atribuídos às entidades do setting. Segundo o autor, as interações espontâneas das crianças são capazes de externalizar estágios intermediários de construção, cuja importância é fundamental na emergência de novidades e na integração conceitual. Na brincadeira compartilhada, os significados são negociados, transformados e reincorporados pelos participantes ao espaço simbólico por meio da linguagem e do discurso, conferindo à interação entre parceiros importante papel no processo microgenético e na integração conceitual.

Assim, o brincar, com destaque, nas presentes considerações, para o faz-de-conta, além de se constituir em atividade buscada e preferida pelas crianças, está relacionado, de diferentes formas, ao desenvolvimento infantil. Nesse sentido, Pinto e Góes (2006), a partir de uma perspectiva histórico-cultural, estudaram os modos de brincar de um grupo de 12 crianças, entre quatro e seis anos, com dificuldades na cognição e linguagem e/ou problemas motores. As crianças foram observadas e videogravadas em situação de brincadeira livre ao longo de sete meses, semanalmente, em uma instituição de educação especial. As autoras analisaram a relação entre os modos de mediação do adulto ou parceiro e a capacidade dessas crianças de transcender o real e compor ações de faz-de-conta. A partir das análises, Pinto e Góes (2006) relatam que, dependendo das formas de interação estabelecidas entre os participantes do grupo, manifestações de elaboração imaginativa, relativamente complexas, emergiam, com características que sugerem contribuições para o desenvolvimento infantil favorecimento da compreensão de mundo e da conceitualização do real, refinamento da capacidade para imaginar, criar situações ficcionais e organizar brincadeiras.

Na mesma direção, Hueara, Souza, Batista, Melgaço e Tavares (2006) observaram em sessões semanais de brincadeira faz-de-conta, os modos de brincar de quatro crianças, entre quatro e seis anos, com deficiência visual (cegueira ou baixa visão) e/ou outras alterações orgânicas. As análises, com foco na construção de conhecimentos e habilidades das crianças, evidenciaram grande capacidade de representar papéis, criar cenas, estabelecer regras, compreender o uso de objetos cotidianos, reconhecer e transmitir aspectos culturais. Assim, os autores sugerem que a interação entre parceiros, em contexto lúdico, mediada por adultos que buscam principalmente facilitar e propiciar o brincar, proporciona um ambiente favorável às múltiplas elaborações das crianças com necessidades especiais e favorece a descrição e promoção de seu desenvolvimento.

Os estudos mencionados ressaltam a importância da interação entre crianças no processo de desenvolvimento infantil. No caso de crianças com necessidades especiais, no entanto, corre-se o risco de que esse processo seja desfavorecido pelas oportunidades reduzidas de interação com parceiros, embora essas crianças apresentem possibilidades de estabelecê-las, quando oferecidos contextos propiciadores. Nesse sentido, o presente estudo pretende expandir as observações de estudos anteriores, procurando observar e analisar o papel dos parceiros no desenvolvimento dessas crianças.

\section{Método}

\section{Participantes}

Participaram do projeto nove crianças de 4 a 12 anos, todas com diagnóstico de deficiência visual (cegueira ou baixa visão), a maioria delas apresentando problemas orgânicos adicionais. As crianças eram integrantes de grupos de convivência, inseridos em um programa integrado de intervenção e pesquisa, em um serviço universitário. Os grupos, descritos mais detalhadamente em Batista e Laplane (2007), visam propiciar condições que favoreçam o processo de desenvolvimento e de inserção dessas crianças em escolas regulares ou em outros recursos educacionais da comunidade. As crianças desse estudo constituíam dois grupos com quatro e cinco participantes respectivamente, que ocorriam em sessões semanais de 90 minutos, realizadas em dias alternados. As atividades propostas para os grupos envolviam projetos temáticos (como meios de transportes e corpo humano), criação de histórias, e atividades lúdicas. Atuavam no grupo um docente, duas aprimorandas ${ }^{2}$ e uma mestranda que se revezavam na intervenção e registro em vídeo de todas as sessões, para todos os projetos realizados.

Grupo I: constituído por crianças entre 4 e 6 anos, que brincavam predominantemente de forma isolada, havendo alguns momentos de interação entre elas incentivados pelo adulto.

Rosane $^{3}, 4$ anos e 2 meses $^{4}$, diagnóstico de baixa visão por retinopatia da prematuridade associada a deslocamento de retina no olho esquerdo. Tinha condições de explorar visualmente objetos, aproximando-os. Não freqüentava escola regular e tinha poucas oportunidades de aprendizagem de conhecimentos normalmente veiculados na escola.

Sônia, 4 anos e 2 meses, diagnóstico de retinopatia da prematuridade e descolamento de retina bilateral, com baixa visão severa. Apresentava grande dificuldade de reconhecimento de objetos. Estava iniciando a adaptação à préescola, com alguma dificuldade de permanecer no grupo sem a presença da avó (sua responsável legal).

Igor, 4 anos e 2 meses, diagnóstico de cegueira no olho direito por agenesia de globo ocular, e baixa visão severa. Seu contato com objetos era guiado, centralmente, pelo tato. Não freqüentava escola.

Mário, 6 anos e 8 meses, diagnóstico de baixa visão, estrabismo convergente, ptose palpebral, agenesia do corpo caloso e retardo no desenvolvimento neuropsicomotor Reconhecia objetos e figuras em diferentes distâncias.

\footnotetext{
${ }^{2}$ Programa de Aprimoramento Profissional - Faculdade de Ciências Médicas (FMC), Universidade Estadual de Campinas (Unicamp)/Fundação de Desenvolvimento Administrativo (Fundap).

${ }^{3}$ Todos os nomes de crianças são fictícios (os nomes de adultos foram mantidos). A família assinou Termo de Consentimento Livre e Esclarecido. Projeto aprovado pelo Comitê de Ética da Faculdade de Ciências Médicas da Universidade Estadual de Campinas (FCM-Unicamp).

${ }^{4}$ Idade no início das observações, realizadas por um período de dois meses.
} 
Freqüentava pré-escola regular desde os três anos de idade, apresentando dificuldades cognitivas e sociais.

Grupo II: constituído por crianças de 7 a 12 anos. Essas crianças estavam matriculadas em escola regular ou especial e apresentavam dificuldades de aprendizagem. Uma delas, Letícia, possuía alterações severas no desenvolvimento, e era acompanhada individualmente, sendo exposta, sempre que possível, às mesmas atividades desenvolvidas pelo grupo.

Sofia, 8 anos e 1 mês, diagnóstico de baixa visão e acromatopsia, diabetes e hiperatividade (diagnóstico por psiquiatra). QI Verbal (WISC) de $96^{5}$. Reconhecia figuras e letras, e, numa avaliação funcional, mostrava discriminação de cores. Freqüentava escola regular com queixas de agressividade no relacionamento com colegas.

Letícia, 10 anos e 1 mês, diagnóstico de cegueira por atrofia do nervo óptico, paralisia cerebral e retardo no desenvolvimento neuropsicomotor. Falava poucas palavras e freqüentava instituição especializada para crianças com deficiência múltipla.

Gisela, 10 anos e 7 meses, diagnóstico de baixa visão por toxoplasmose ocular. QI Verbal (WISC) de 77. Apresentava diagnóstico de retardo no desenvolvimento neuropsicomotor. Reconhecia objetos e figuras, aproximando-os bastante dos olhos. Freqüentava escola regular, matriculada na $2^{\mathrm{a}}$ série, com queixas de curta permanência nas atividades propostas e dificuldades de aprendizagem.

Edith, 11 anos e 4 meses, diagnóstico de baixa visão por úlcera de córnea associada à analgesia da mesma e síndrome de Riley-Day. QI Verbal (WISC) de 69. Freqüentava escola regular, matriculada na $3^{\mathrm{a}}$ série, apresentando dificuldades de aprendizagem.

Daniel, 12 e 6 meses, diagnósticos de baixa visão (catarata congênita), hemiparesia do lado direito e episódios de convulsão sob controle medicamentoso. QI Verbal (WISC) de 53. Freqüentou a Associação de Pais e Amigos de Excepcionais (APAE) dos 5 aos 8 anos. Com 8 anos ingressou na escola normal regular, onde permaneceu até os 10 anos, quando voltou a freqüentar a APAE.

\section{Procedimentos}

Foram previamente selecionados brinquedos apropriados para a faixa etária das crianças e com características que favorecessem o faz-de-conta: móveis de cozinha e utensílios em miniatura; móveis de quarto com respectivos acessórios; bonecos articuláveis de madeira e bonecas tipo Barbie; carrinhos e caminhões; blocos de madeira; piões e acessórios de beleza. Os brinquedos foram disponibilizados em 12 sessões de brincadeira livre. Inicialmente foram previstas a realização de cinco sessões de brincadeira para cada grupo. No entanto, como surgiram mais variações nas modalidades de interação entre as crianças do grupo II, optouse por expandir a coleta de dados, apenas nesse grupo, para sete sessões. As sessões realizadas no grupo I duraram de 40 a 50 minutos, enquanto que as realizadas no grupo II tiveram duração de 25 a 30 minutos. A diferença no tempo de realização das sessões para os diferentes grupos se deu pelo fato de que no grupo I, constituído por crianças mais novas, os brinquedos foram disponibilizados durante todo o tempo de atividade em sala. Já no grupo II, por se tratar de crianças mais velhas, as sessões de brincadeiras eram precedidas por atividades mais estruturadas, e os brinquedos oferecidos na meia hora final dos atendimentos. Todas as sessões deste projeto foram registradas em vídeo, transcritas e analisadas. As filmagens foram realizadas por câmera móvel, procurando focar o conjunto dos membros do grupo. Quando se formavam grupos paralelos, optavase por filmar cada subgrupo por um período que configurasse a ocorrência de um ou mais episódios em sua íntegra. Foi também mantido um Diário de Campo, com anotações sobre eventos relevantes de cada sessão.

Os dados obtidos foram organizados em episódios, escolhidos como unidade de análise, buscando-se selecionar aspectos representativos das interações entre as crianças em suas várias manifestações, habilidades e capacidades explicitadas, modalidades de faz-de-conta e seus graus de elaboração. O conceito de episódio adotado foi o definido por Pedrosa e Carvalho (2006) como uma seqüência interativa ou trecho de registros em que se pode delimitar um grupo de crianças pela organização espacial ou participação em uma atividade. A determinação do início ou término do episódio era determinada por um fato que desencadeava uma sequiência interativa, como uma mudança na temática da brincadeira, a interrupção por um agente externo, ou a mudança na composição do grupo. À semelhança dessas autoras, considerou-se ter havido um certo grau de arbitrariedade na determinação dos episódios.

\section{Resultados}

A análise dos episódios possibilitou a identificação de dois grupos de categorias, que exemplificavam: (a) os modos de brincar (individual ou em grupo) e (b) os modos de se relacionar (amistoso ou agonístico) das crianças. Do conjunto de episódios analisados, foram selecionados para o presente relato um episódio representativo de cada categoria.

\section{Categorias Referentes aos Modos de Brincar \\ (Individual ou em Grupo)}

Ação individual. Situações em que a criança utilizou os brinquedos, de modo convencional ou não, sem a participação do parceiro ${ }^{6}$. O seguinte episódio pode exemplificar essa situação:

Grupo I: Episódio: Girafa, camelo, peixe...

Nessa sessão foram disponibilizados para as crianças miniaturas de animais.
${ }^{5} \mathrm{O}$ teste Wisc Verbal, padronização brasileira de Figueiredo (2002) foi aplicado para todas as crianças no ano de 2004, com exceção de Sofia, que entrou no grupo em 2005 e para a qual o teste foi aplicado no ano de 2007. ${ }^{6}$ Apesar de o estudo estar voltado para a interação entre crian-
ças, observou-se entre as crianças do grupo I o predomínio
de ações individuais com objetos, geralmente mediadas pelo
adulto. 
Souza, C. M. L. \& Batista, C. G. (2008). Interação entre Crianças com Necessidades Especiais em Contexto Lúdico: Possibilidades de Desenvolvimento.

Mário permanece durante alguns minutos, sozinho, retirando miniaturas do baú, manipulando e nomeando os animais. Por exemplo: Mário pega um animal e pergunta: "Tia, e esse aqui?". Cecilia (ad. $\left.{ }^{7}\right)$ devolve a pergunta para ele: "E esse aí?" Mário responde: "Girafa”. Em seguida ele pega um camelo, observa-o e repete a situação descrita com a girafa.

Nesse episódio, Mário explora as miniaturas de animais, observando, manipulando e nomeando esses objetos. Mário permanece nessa brincadeira por algum tempo e por diversas vezes, ao longo das sessões, a retoma. Ao retirar espontaneamente os brinquedos do baú e iniciar o diálogo com o adulto, Mário assume uma postura ativa que merece ser ressaltada, já que as ações de Mário se caracterizavam, muitas vezes, pelo manuseio e exploração passiva de objetos colocados em sua mão, utilizando as mãos e a boca. Outras vezes, quando pegava objetos, fazia perguntas repetidas ao adulto (“Que é isso?”), sem responder às questões e comentários do adulto. No exemplo, Cecilia devolve a pergunta feita por Mário, e ele responde, evitando-se, assim, as reiterações observadas em outras situações.

Ação com participação do parceiro. Momentos em que a atividade da criança foi influenciada pela observação do parceiro, com alguma forma de ação conjunta (sem chegar à construção de cenas).

Grupo I: Episódio: Cadê a calcinha dela?

Enquanto manipula uma boneca, Rosane pergunta: "Cadê calcinha? A calcinha dela." Mário, que manipula uma boneca próximo de Rosane, a observa e diante de sua fala, levanta a roupa da boneca e parece procurar pela calcinha. Eneida (ad) não entende a fala de Rosane e pergunta pela "casinha": "Tem que construir uma casinha pra ela." Rosane levanta a roupa da boneca e pergunta novamente: "Cadê a calcinha dela?" Dessa vez, Eneida entende: "Ah, a calcinha dela!"

Mário passava grande parte das sessões em atividades isoladas, que envolviam a exploração e nomeação de objetos, e dificultavam a compreensão do quanto a convivência com outras crianças o atingia. A presença de parceiros parecia, na maioria das vezes, indiferente para Mário. Dessa forma, esse trecho é interessante por trazer indicações de que Mário estava atento às outras crianças, cujas falas e atitudes podiam influenciar suas ações. Mário ouviu Rosane, deu significado para sua fala e agiu de forma coerente com esse significado (procurou a calcinha em sua boneca).

Ação conjunta. Situações em que a interação entre pares propiciou a elaboração conjunta de cenas, envolvendo, em diferentes proporções, aspectos do cotidiano e do imaginário.

Grupo II: Episódio: A Pesca

Gisela encontra entre os brinquedos uma miniatura de espada e diz que é uma vara de pescar. Sofia se aproxima e pede para vê-la. Sofia observa o objeto e percebe que se trata de uma espada. Eneida (ad) pergunta sobre o que po-

${ }^{7}$ Ad: adulto. deria ser feito com a vara. Gisela diz que pode pescar. Eneida sugere que elas podem pescar e Sofia pode cozinhar um peixe. Sofia sorri parecendo gostar da idéia e Gisela aceita animadamente: "É mesmo!." Sofia fala: "Eu vou ir na casa da Gisela pra ela cozinhar!”.

Esse episódio é de especial importância, já que em outros momentos a interação entre essas crianças se caracterizou principalmente por situações de disputa permanente. A tendência de Sofia em monopolizar os objetos e brincar sozinha criava, por diversas vezes, um ambiente de tensão que só cessava com a intervenção do adulto. No entanto, nesse episódio ela agiu de modo diferente, favorecendo a interação, o que foi notado especialmente quando Sofia percebeu que a "vara", na verdade, era uma espada. Sofia comentou isso com Eneida, mas não confrontou com Gisela: ao contrário, sustentou o faz-de-conta estabelecido. Anteriormente, situações semelhantes tinham sido motivo para que Sofia se desentendesse com parceiros, criticando-os e desvalorizando-os.

Ação conjunta com predomínio de diálogos elaborados. Episódios em que o aspecto que se destaca é a manutenção de diálogos temáticos surgidos a partir da atividade, mais do que o tipo de manuseio dos objetos.

Grupo II: Episódio: Rebeldes

Gisela brinca com blocos de madeira e conversa com Cecilia (ad) sobre um programa infantil da rede Cultura. Edith as interrompe e pergunta se Gisela assiste "Rebeldes" (novela infanto-juvenil transmitida pelo Sistema Brasileiro de Televisão - SBT). A partir daí, a atividade com blocos passa a ser pouco enfatizada e as duas estabelecem um diálogo sobre os personagens (Vick, Gastão, Celina, Miguel, Lupita) e a trama da novela, além de discorrerem sobre outros programas de televisão (Jornal do SBT, Programa Roda-roda e novela Belíssima) e seus respectivos horários, conteúdos e apresentadores. Abaixo segue um pequeno trecho do diálogo:

Edith: Ela gosta do Gastão.

Gisela: Não gosta, não.

Edith: Só que o Miguel foi lá perguntar pra ela se ela tava falando com o Miguel, quer dizer, com o Gastão. Ela falou assim: "O que que você tá falando, Miguel?" (imita a fala do personagem). Ela tava fazendo de conta que ela não tava sabendo de nada.

Gisela: Mas ele pensou que ela ia no, coiso lá, com a Vick lá, com a Celina, no cabeleireiro, mas ela não foi.

Edith: Mas não foi, era tudo mentira.

Essa categoria foi destacada por indicar, para as crianças do grupo, uma mudança na modalidade de participação. Nesse episódio, Gisela, que em situações anteriores mantinha interações com pares e elaborações complexas sempre com forte base nos objetos, mostrou uma mudança qualitativa de desempenho, ao sustentar a interação, sem o apoio do concreto, na forma de uma conversa coerente e relativamente longa com o parceiro. Por sua vez, Edith, que por vários anos, só mantinha interações breves, com poucas iniciativas de interação, mostrou desenvoltura e reciprocidade na manutenção dos diálogos. No exemplo, 
as duas sustentaram um diálogo sobre tema típico de sua faixa etária de pré-adolescentes, deixando de lado atividades mais típicas de crianças mais novas.

O exame das transcrições e de episódios selecionados, bem como das notas do Diário de Campo, indicaram, para o grupo I, um predomínio de ações individuais, mediadas pelo adulto, e algumas instâncias de ação envolvendo a participação do parceiro. Quanto ao grupo II, foi observado o predomínio de interações mais complexas, envolvendo partilhas, ações conjuntas, construção de cenas e disputas. Dessa forma, os episódios relativos aos modos de se relacionar, alvo da segunda modalidade de análise, foram observados nesse grupo.

\section{Categorias Referentes aos Modos de se Relacionar (Amistoso ou Agonístico)}

Disputa de brinquedos. Situações de discordância e disputas entre as crianças.

Grupo II: Episódio: Como se arruma a mesa?

Michelli (ad) sugere que Gisela e Sofia organizem uma festa de aniversário para Cecilia (ad). Durante a organização, elas alternam atuação conjunta com disputas.

Sofia: Ai, Gisela, deixa que eu arrumo, tá bom? Eu que sei arrumar!

Gisela: Ah, eu também sei arrumar, mas você não deixa, você fica aí, ó!

Sofia: Você arruma torto!

Gisela: Eu não arrumo não!

Sofia: Arruma! . . . Arruma sim, que você... falou!

Gisela: Mentira! Eu não falei nada disso não, Sofia! É meu jeito de arrumar, tá? [Gisela e Sofia colocam juntas panelinhas em cima da caixa].

Momentos de disputa entre Gisela e Sofia foram freqüentes. O trecho acima exemplifica uma das muitas situações de desavença entre elas. Além de desvalorizar a capacidade de Gisela de arrumar a mesa, Sofia atribui à colega um comentário que, na realidade, não foi feito (diz que Gisela assumiu que arrumava a mesa "torto"). Gisela não se deixa abater pelo discurso de Sofia e cria uma justificativa coerente para a crítica da parceira. Ao dizer que aquele era o jeito dela arrumar, Gisela coloca que diferentes formas podem ser aceitas, desfazendo a polarização entre certo e errado trazida por Sofia.

Iniciativa de ajuda. Falas e ações das crianças com o intuito de oferecer objetos ao parceiro ou de ajudá-lo em alguma atividade.

Grupo II: Episódio: Gentleman

Gisela e Sofia tentam abrir o baú, mas têm dificuldades em manter a tampa aberta enquanto pegam alguns brinquedos. Daniel observa a situação e oferece ajuda: "Hei, quer ajuda?" Em seguida, ele abre o baú e segura a tampa para que elas retirem os brinquedos.

Nesse episódio se destaca a participação de Daniel que, ao notar a dificuldade das meninas em manter aberta a tampa do baú, imediatamente se oferece para ajudá-las. A atitude de Daniel é apenas um exemplo de que crianças com necessidades especiais também são capazes de resolverem entre si, com a ajuda uns dos outros, situações sim- ples que não necessitariam da interferência de adultos, mas nas quais muitas vezes estes agem por subestimarem as habilidades dessas crianças.

Compartilhar conhecimentos. Atuação da criança no sentido de oferecer ao parceiro algumas noções através de explicações e/ou demonstrações.

Grupo II: Episódio: O barco da lagoa

Edith pergunta onde moram Ana (ad) e Cecilia (ad). Cecilia diz que mora perto da lagoa do Taquaral e pergunta se alguém já esteve lá. Edith responde: "Eu não fui não. Eu nunca fui nesse lugar." Gisela diz: "Já, eu já passei lá de perua." Cecilia diz que na lagoa tem um barco. Gisela concorda e pergunta: "É. Mas cai esse barco aí?" Edith responde: "Cai não, segura a água, a água não passa em cima do barco não. Não é verdade? Não é?"Ana concorda com Edith: "É verdade. A menos que afunde, mas esse do Taquaral não vai afundar."

Nesse episódio Edith e Cecilia conversam sobre alguns lugares de Campinas, entre eles a Lagoa do Taquaral, onde há uma réplica de caravela. Gabriela, que está próxima a elas, se interessa pelo assunto e faz uma pergunta ("Mas esse barco cai?") que demonstra dúvidas relativas ao tema. É interessante que Edith rapidamente compreende essa dúvida e tenta esclarecer para a parceira que os barcos ficam sobre a água e por isso não "caem." Situações como essas são importantes para crianças como Edith, criança bastante subestimada no ambiente escolar. Nesse trecho, Edith teve a oportunidade de desempenhar o papel, provavelmente pouco frequiente no seu cotidiano, de alguém que detém um conhecimento rudimentar sobre flutuação, e é capaz de explicar ao outro algo novo.

Maternagem. Situações em que algumas crianças apresentaram para com seus pares comportamentos que se assemelhavam aos comportamentos de cuidado e proteção do adulto.

Grupo II: Episódio: Olha aqui, Letícia!

Gisela está brincando com blocos. Cecília (ad), que está atrás dela, chama Letícia para ver os brinquedos do baú. Gisela pega um dos blocos e oferece à Letícia: “Olha aqui Letícia. Olha aqui o brinquedo." Letícia não dá atenção, e Gisela pede à Cecilia: "Mostra pra ela o brinquedo." Cecilia entrega o bloco para Letícia. Gisela oferece outros blocos: "Olha aqui Letícia, olha só, parece um macaquinho." Cecilia chama a atenção de Letícia para o bloco que Gisela está lhe apresentando. Gisela continua: "Olha aqui, um triângulo! Tem três lados. Olha aqui Letícia!"

Conforme se depreende da caracterização de Letícia, ela apresentava severo atraso e alterações no desenvolvimento, com participação limitada a poucos contatos com objetos e raras verbalizações contextualizadas, sem permitir uma interação simétrica. Ao longo das sessões de brincadeira, foram observados vários momentos como este em que Gisela ou Edith dispensaram cuidados especiais para Letícia. Em algumas situações, elas ofereciam brinquedos e incentivavam a exploração de objetos, em outros, cuidavam para que não se machucasse. Nesse exemplo, considerou-se que Gisela não apenas ofereceu um bloco: ela reconheceu a dificuldade do outro, percebeu o empenho do 
Souza, C. M. L. \& Batista, C. G. (2008). Interação entre Crianças com Necessidades Especiais em Contexto Lúdico: Possibilidades de Desenvolvimento.

adulto em propiciar a participação de Letícia, assumiu o papel do adulto e proporcionou uma breve explicação sobre o objeto. Gisela fez uma série de ajustes para a situação de ensino, e mesmo não havendo significativa diferença de faixa etária em relação a Letícia, colocou-se no papel de tutoria em relação à colega. Considera-se que situações como essa adquirem um significado importante para crianças com deficiência, pois permitem que elas assumam papéis ligados à noção de competência.

\section{Discussão}

A situação de brincadeira livre em grupo se mostrou um espaço favorável para que crianças com deficiência estabelecessem e sustentassem interações com seus parceiros, de forma similar ao observado para as crianças com desenvolvimento típico.

No grupo de categorias relativo aos "modos de brincar", observou-se que a categoria ação individual mostrou semelhança com uma das categorias descritas por Lordelo e Carvalho (2006). As autoras realizaram estudo descritivo dos padrões de parceria social e tipos de brincadeiras entre crianças com desenvolvimento típico, na faixa etária de um a três anos, em situação de brincadeira livre no ambiente de creche, e descreveram, como uma das categorias típicas, a ação "individual" com o brinquedo. O episódio apresentado no presente estudo é representativo de muitas situações observadas, que evidenciaram momentos de aquisição das crianças, em interação com objetos, mediadas por adultos. Nesse episódio, Mário explora objetos e dialoga com o adulto de forma mais elaborada que o observado normalmente. Essa competência não era observada de forma regular e previsível: ocorria em alguns momentos, e não em outros, embora estivesse se tornando cada vez mais constante e elaborada. Isso contrasta com as situações em que o adulto tomava a iniciativa, e nas quais Mário tendia a recusar colaboração: geralmente não respondia a solicitações, tendia a evitar contato chegando a virar-se de costas para o interlocutor. Assim, o modo individual, de fato, referiu-se a situações em que a interação predominante foi com o adulto, e não com os parceiros.

Quanto à segunda categoria, ação com participação do parceiro, esta permitiu identificar momentos em que as crianças se mostraram sensíveis à presença das outras crianças, embora não em atuação compartilhada. Essa questão também foi abordada por Lordelo e Carvalho (2006), que observaram que, mesmo quando as crianças brincavam paralelamente, sem a coordenação de ações, havia uma orientação social: a criança ocasionalmente olhava a outra e observava suas ações, podendo em seguida mudar sua atividade ou forma de brincadeira em decorrência delas. De acordo com as autoras, essa atitude indica que a criança pode exercer alguma regulação no comportamento do parceiro. O mesmo foi observado no presente estudo, como exemplificado pelo episódio protagonizado por Mário, uma criança geralmente descrita como pouco responsiva às tentativas de interação de adultos e parceiros.
Os exemplos referentes à categoria ação conjunta, à semelhança do observado por Lordelo e Carvalho (2006) para a categoria "díade", revelaram momentos nos quais as crianças foram capazes de articular suas ações, simples ou elaboradas. O episódio "A pesca", envolvendo Sofia, criança caracterizada por constantes episódios de desavença com seus pares, constituiu-se em exemplo de situação em que foi possível o estabelecimento de interações construtivas entre essa criança e seus parceiros. Além disso, as situações de brincadeira estabelecidas entre as crianças confirmaram algumas das considerações de Sinha (2005) referentes ao jogo simbólico, incluindo a capacidade de lidar simultaneamente com aspectos do mundo real e imaginário. Sofia e Gisela, por exemplo, exploraram um objeto - a espada, atribuindo-lhe funções convencionais e imaginárias (vara de pescar), de forma semelhante ao discutido por Sinha (2005), para quem as crianças mesclam o imaginário e o real, superando as características imediatas e convencionais do ambiente físico e negociando novos significados. $\mathrm{O}$ episódio descrito, e os demais analisados no presente estudo, ressaltaram a possibilidade de colaboração entre crianças na elaboração de cenas, no compartilhar de brinquedos, na troca de papéis, e na aplicação de conhecimentos do cotidiano. Episódios como este indicam a presença de atenção sustentada, raciocínio lógico, construção de diálogos coerentes e instâncias de respeito mútuo.

Com relação à categoria ação conjunta com o predomínio de diálogos elaborados, observou-se que o ambiente de brincadeira, livre de exigências quanto ao desempenho, favoreceu a manifestação de habilidades geralmente subestimadas nessas crianças, relacionadas à construção e sustentação de diálogos coerentes e com certo grau de complexidade. No episódio Rebeldes, observou-se o estabelecimento de um diálogo rico em detalhes, evidenciando atenção sustentada e coerência, e indicando conhecimentos referentes a eventos significativos do cotidiano das crianças. A partir da pergunta de Edith, as crianças iniciaram um longo diálogo, com temática e estilo típicos de pré-adolescentes, sobre uma novela e outros programas transmitidos na ocasião das gravações.

Carvalho e Pedrosa (2002), em um estudo referente à natureza, transformação e transmissão de fenômenos culturais na brincadeira, analisaram episódios de crianças de 10 a 60 meses em atividade lúdica livre, sendo um deles relativo à organização de uma brincadeira cujo enredo era baseado na novela "Roque Santeiro" (transmitida na época). A análise permitiu que as autoras observassem o papel ativo da criança nos processos de criação e transmissão da cultura, que ocorrem no interior da brincadeira. $\mathrm{O}$ mesmo pôde ser observado no diálogo estabelecido entre as crianças do presente estudo. Desse modo, essas crianças apresentaram, em situações alternativas às da escolaridade formal, pelo menos alguns indicadores das competências que pareciam não existir nas avaliações feitas pela escola.

Quanto ao grupo de categorias "modos de se relacionar", no que se refere à categoria disputa, foram observados momentos de discordância entre as crianças, nos quais foi 
possível notar capacidade de argumentação, exercício da assertividade, raciocínio lógico, persuasão, persistência e apropriação de falas e modo de agir do adulto, bem como expressão de agressividade. Carvalho e Beraldo (1989) consideram que o parceiro nem sempre se constitui como um companheiro em uma atividade, podendo muitas vezes despertar atos agressivos, competitivos ou de disputa, o que as autoras denominam de "motivação controvertida".

No episódio apresentado, Sofia subestimou Gisela, que se defendeu de modo pertinente, e, em seguida, continuou a brincadeira em sua companhia. É interessante ressaltar a assertividade e capacidade de se defender de Gisela, lembrando que crianças com deficiência estão em risco de não apresentarem essas capacidades, tendendo ou à agressividade, ou à passividade.

Góes (1995), estudando os modos de participação do outro no funcionamento da criança, alertou para a insuficiência de atenção à diversidade, não linearidade e irregularidade das relações eu-outro. Ressaltou a importância da complexidade das interações entre pares, advertindo quanto à tendência de se atribuir um funcionamento prototípico (que se inicia como regulação pelo outro e assume um caráter de partilha, suporte e harmonia) ao caráter intersubjetivo do desenvolvimento infantil. Diante das considerações da autora, o episódio que exemplifica essa categoria adquiriu um significado especial, por destacar a complexidade das relações entre crianças com deficiência.

Os episódios relativos à iniciativa de ajuda permitiram observar a sensibilidade dessas crianças, em relação às dificuldades de seus parceiros. Isso foi evidenciado no episódio selecionado, em que Daniel se ofereceu para manter a tampa do baú aberta enquanto Gisela e Sofia pegavam brinquedos, e em vários outros episódios. O mesmo foi observado por Carvalho (2000), que investigou o comportamento de cuidado entre crianças de dois a quatro anos, observadas em diferentes ambientes institucionais, com o objetivo de identificar fatores contextuais que pudessem influenciar a ocorrência desse comportamento. Em análise preliminar, o autor identificou subcategorias que revelaram exemplos de cuidado, similares aos observados nas crianças do presente estudo. Em seu estudo, a subcategoria ajudar, por exemplo, envolveu momentos nos quais as crianças tomaram a iniciativa de fazer ou oferecer-se para fazer algo pelo outro, ou quando elas solicitaram a ajuda de uma terceira criança para ajudar o parceiro. No presente estudo, o exemplo envolvendo Daniel traz uma faceta pouco observada desse participante, geralmente descrito por suas dificuldades de aprendizagem, e por sua agitação e movimentação constante, ao longo das atividades propostas nos grupos.

No que concerne à categoria compartilhar conhecimentos, foram identificados momentos de colaboração entre as crianças, em que elas foram capazes de transmitir aos parceiros tanto conhecimentos conceituais, como aqueles relativos às relações sociais. O episódio apresentado é ilustrativo do primeiro caso (conhecimentos conceituais) em que Edith explicou algumas propriedades de uma embarcação para Gisela. Um outro exemplo interessante que ilustra esse caso se refere ao episódio "Olha aqui, Letícia!”, apresentado na categoria maternagem, no qual Gisela mostrou blocos para Letícia e em determinado momento lhe explicou que o triângulo possui três lados.

Carvalho e Pedrosa (2002), ao discutirem a transmissão de elementos culturais pelas crianças em situação de brincadeira, salientaram que nem sempre a presença da macrocultura na microcultura do brinquedo se revela de modo evidente (como no episódio Rebeldes). Em muitos casos, senão na maioria deles, ocorre de forma mais discreta através de explicações informais, distribuição dos papéis, da atribuição de valores e da constituição e aceitação das regras pelos participantes, como observado em muitos episódios do presente estudo.

Por fim, na categoria maternagem, o episódio descrito permitiu ressaltar os esforços de Gisela em favorecer a participação de Letícia, por meio da oferta de brinquedos, explicações e atitudes encorajadoras. Em outros exemplos, observou-se, também, a preocupação de Edith e Gisela com as preferências e interesses de Letícia. O modo de agir das crianças se assemelhou às ações de cuidado do adulto para com crianças pequenas, e, portanto, pode constituir um importante indicativo do quanto o ambiente social e as relações nele estabelecidas são compreendidos por crianças com necessidades especiais. Além disso, esse contexto pode proporcionar uma oportunidade para que elas se constituam como pessoas competentes e responsáveis por outras, o que raramente acontece em sua vida cotidiana, e é muito relevante para seu desenvolvimento. Dessa forma, as crianças demonstraram competências relativas à compreensão das limitações do parceiro, tolerância, paciência, noção e intenção de cuidado, iniciativas de interação e transmissão de conhecimentos. No estudo anteriormente mencionado, Carvalho (2000) identificou, para crianças com desenvolvimento típico, situações em que uma delas chamou a atenção do parceiro para a participação em atividades lúdicas (subcategoria entreter), de modo semelhante ao ocorrido no episódio “Olha, Letícia!" Por sua vez, Carvalho e Beraldo (1989) afirmam que as relações de maternagem estabelecidas entre crianças indicam a capacidade de "discriminação das características dos parceiros sociais e de ajustamento de seu comportamento a essas características ... de reconhecer e assumir a perspectiva do outro, e de reagir empaticamente" (p. 59).

É interessante destacar que trabalhos anteriores, abordando a interação entre parceiros com desenvolvimento típico (Carvalho, 2000; Lordelo \& Carvalho, 2006; Pedrosa \& Carvalho, 1995), identificaram categorias que indicaram processos similares aos observados pelo presente estudo no caso das crianças com necessidades especiais, mesmo que com possível defasagem de idade.

De modo geral, em relação ao presente estudo, considerou-se que a observação constante do brincar, com um olhar atento às potencialidades da criança, permitiu evidenciar importantes indícios de desenvolvimento. A situação naturalística de brincadeira em grupo revelou-se um espaço favorável para que crianças com alterações no desenvolvimento estabelecessem e sustentassem diferentes modalidades 
Souza, C. M. L. \& Batista, C. G. (2008). Interação entre Crianças com Necessidades Especiais em Contexto Lúdico: Possibilidades de Desenvolvimento.

de interação com seus parceiros, em processos análogos aos referidos na literatura sobre desenvolvimento infantil e, provavelmente, trazendo benefícios análogos.

\section{Referências}

Batista, C. G., \& Laplane, A. L. F. (2007). Modalidades de atendimento especializado: $O$ grupo de convivência de crianças com deficiência visual. In E. F. S. Masini (Ed.), A pessoa com deficiência visual: Um livro para educadores (pp. 85-111). São Paulo, SP: Vetor.

Carvalho, A. M. (2000). Fatores contextuais na emergência do comportamento de cuidado entre crianças. Psicologia: Reflexão e Crítica, 13, 81-88.

Carvalho, A. M. A., \& Beraldo, K. E. A. (1989). Interação criança-criança: De uma área de pesquisa e suas perspectivas. Cadernos de Pesquisa, 71, 55-61.

Carvalho, A. M. A., \& Pedrosa, M. I. (2002). Cultura no grupo de brinquedo. Estudos de Psicologia (Natal), 7, 181-188.

Góes, M. C. R. (1995). A construção de conhecimentos: Examinando o papel do outro nos processos de significação. Temas em Psicologia, 2, 23-29.

Guralnick, M. J. (1997). Peer social networks of young boys with developmental delays. American Journal on Mental Retardation, 101, 595-612.

Guralnick, M. J. (2002). Involvement with peers: Comparisons between young children with and without Down syndrome. Journal of Intellectual Disability Research, 46, 379-393.

Hueara, L., Souza, C. M. L., Batista, C. G., Melgaço, M. B., \& Tavares, F. S. (2006). O faz-de-conta em crianças com deficiência visual: Identificando habilidades. Revista Brasileira de Educação Especial, 12(3), 351-368.

Huizinga, J. (1971). Homo ludens: O jogo como elemento da cultura (4. ed.). São Paulo, SP: Perspectiva Editora da Universidade de São Paulo.

Lordelo, E. R., \& Carvalho, A. M. A. (2006). Padrões de parceria social e brincadeira em ambientes de creches. Psicologia em Estudo (Maringá), 11, 99-108.

Pedrosa, M. I., \& Carvalho, A. M. A. (1995). A interação social e a construção da brincadeira. Cadernos de Pesquisa, 93, 60-65.

Pedrosa, M. I., \& Carvalho, A. M. A. (2006). Análise qualitativa de episódios de interação: Uma reflexão sobre procedimentos e formas de uso. Psicologia: Reflexão e Crítica, 18, 431-442.

Pinto, G. U., \& Góes, M. C. R. (2006). Deficiência mental, imaginação e mediação social: Um estudo sobre o brincar. Revista Brasileira de Educação Especial, 12, 11-28.

Preisler, G. (1997). Social and emotional development of blind children: A longitudinal study. In V. Lewis \& G. M. Collis (Eds.), Blindness and psychological development in young children (pp. 116-129). London: The British Psychological Society.

Sinha, C. (2005). Blending out of the background: Play, props and staging in the material world. Jornal of Pragmatics: An Interdisciplinary Monthly of Language Studies, 37, 1537-1554.

Vygotsky, L. S. (1991). A formação social da mente. O desenvolvimento dos processos psicológicos superiores (4. ed., J. Cipolla Neto, L. S. Menna Barreto, \& S. C. Afeche, Trads.). São Paulo, SP: Martins Fontes. (Original publicado em 1978)

Vygotsky, L. S. (1997). Obras escogida: Vol. 5. Fundamentos de Defectología (J. G. Blank, Trad., N. J. V. Vargas \& I. Filanova, Revisores). Madri, España: Visor. (Original publicado em 1974).

Recebido: 10/08/2007 $1^{a}$ revisão: $31 / 01 / 2007$ $2^{a}$ revisão: $01 / 04 / 2008$ Aceite final: 14/04/2008 